\title{
Embelin Alleviates Severe Airway Inflammation in OVA-LPS-Induced Rat Model of Allergic Asthma
}

\author{
Shazalyana Azman ${ }^{1,2}$ \\ Mahendran Sekar (D) \\ Suzana Wahidin ${ }^{2}$ \\ Siew Hua Gan (D) ${ }^{3}$ \\ Jaishree Vaijanathappa ${ }^{4}$ \\ Srinivasa Reddy Bonam (iD) \\ Mallika Alvala ${ }^{6}$ \\ Pei Teng Lum' \\ Vandana Thakur ${ }^{7}$ \\ Jayesh $\vee$ Beladiya $^{7}$ \\ Anita A Mehta ${ }^{7}$ \\ 'Department of Pharmaceutical Chemistry, \\ Faculty of Pharmacy and Health Sciences, \\ Universiti Kuala Lumpur Royal College of \\ Medicine Perak, Ipoh, Perak, 30450, \\ Malaysia; ${ }^{2}$ Bioengineering and Technology \\ Section, Universiti Kuala Lumpur Malaysian \\ Institute of Chemical \& Bioengineering \\ Technology, Alor Gajah, Melaka, 78000 , \\ Malaysia; ${ }^{3}$ School of Pharmacy, Monash \\ University Malaysia, Bandar Sunway, \\ Selangor Darul Ehsan, 47500, Malaysia; \\ ${ }^{4}$ Faculty of Life Sciences, JSS Academy of \\ Higher Education and Research Mauritius, \\ Republic of Mauritius; 5 Institut National de \\ la Santé et de la Recherche Médicale; \\ Centre de Recherche des Cordeliers, \\ Equipe-Immunopathologie et \\ Immunointervention Thérapeutique, \\ Sorbonne Université, Université De Paris, \\ Paris, F-75006, France; ${ }^{6}$ MARS Training \\ Academy, Hyderabad, 500037, India; \\ ${ }^{7}$ Department of Pharmacology, \\ L. M. College of Pharmacy, Ahmedabad, \\ Gujarat, India
}

Correspondence: Mahendran Sekar Department of Pharmaceutical Chemistry, Faculty of Pharmacy and Health Sciences, Universiti Kuala Lumpur Royal College of Medicine Perak, No. 3 Jalan Greentown, Ipoh, Perak, 30450, Malaysia

Tel $+6016-3346653$

Fax $+605-2536634$

Email mahendransekar@unikl.edu.my
Background: Asthma is a chronic lung disease, which causes wheezing, tightness in the chest, shortness of breath and coughing. In the wake of coronavirus disease 2019 (COVID19), which affect the lungs, asthma patients are at high risk. Embelin, a natural benzoquinone obtained mainly from Embelia ribes Burm, has excellent biological properties, including protection against acute asthma. However, since asthma is a chronic and multi-factorial inflammatory disease, asthma conferred by a single allergen in an animal may not be clinically significant. Therefore, the purpose of the current study was to evaluate the effectiveness of embelin against ovalbumin (OVA)-lipopolysaccharide (LPS)-induced severe airway inflammation in experimental animals and to investigate the plausible mechanism of action.

Methods: Rats ( $\mathrm{n}=36)$ were divided into six groups. Group I served as a normal control. Groups II-VI were sensitised with severe allergens (OVA and LPS) on day 7, 14 and 21, followed by OVA and LPS challenge for $30 \mathrm{~min}$ three times/week for 3 weeks. Group II acted as an asthmatic disease control and received only vehicle. On the other hand, groups III-V received embelin $(12.5,25$ and $50 \mathrm{mg} / \mathrm{kg}$, P.O. respectively) while group VI received a standard dexamethasone $(2.5 \mathrm{mg} / \mathrm{kg}$, P.O.) for 15 days from day 27 . Lung function parameters, including the respiratory rate, tidal volume and airflow rate were measured at the end of the experiment (day 42). The total and differential counts of leukocytes in the blood and bronchoalveolar fluid (BALF) were calculated. Th2-mediated serum proinflammatory cytokines such as interleukin (IL)-4, IL-5 and IL-13 levels were analyzed. At the end of the study protocol, the lung tissues were removed for a histopathology study. Additionally, a molecular docking simulation on embelin and standard dexamethasone was applied to support the in vivo findings.

Results: Significant inhibition of eosinophils, neutrophils, lymphocytes and monocytes in the blood and the BALF was seen in the groups, which received embelin (25 and $50 \mathrm{mg} /$ $\mathrm{kg})$ and dexamethasone $(2.5 \mathrm{mg} / \mathrm{kg})$. Moreover, the lung function parameters were normalised by embelin $(25$ and $50 \mathrm{mg} / \mathrm{kg})$ treatment significantly. The lung histopathological changes confirmed the protective effect of embelin against severe airway inflammation. The docking findings indicated good binding efficacy of embelin to IL-13.

Conclusion: Overall, our findings indicate that embelin can alleviate severe airway inflammation in OVA-LPS-induced model of allergic asthma occurring by suppression of Th2mediated immune response. Due to its promising anti-asthmatic effect, it is recommended that embelin should be investigated in clinical trials against asthma. It should also be further explored against COVID-19 or COVID-like diseases due to its ameliorative effects on cytokines and immune cell infiltration.

Keywords: embelin, OVA-LPS-induced severe asthma, allergic inflammation, Th2-mediated inflammatory cells, IL-13 molecular docking, COVID-19 


\section{Introduction}

Asthma is a chronic inflammatory airway disease, affecting 300 million people worldwide and is expected to hit almost 400 million individuals in the next 5 years. ${ }^{1}$ Globally, asthma accounted for 1 out of 250 deaths. ${ }^{1}$ In addition, current pandemic caused by serious acute respiratory syndrome coronavirus 2 (SARS-CoV-2), which is causing coronavirus disease 2019 (COVID-19), accounted for 5.21 million deaths and 261.74 million people affected worldwide as of November 29, 2021. In theory, asthmatic patients tend to have increased susceptibility and worst outcome during SARS-CoV-2 because of an impaired antiviral immune response and the potential for exacerbation caused by common respiratory viruses, where the Centers for Disease Control and Prevention 2020 (CDC) lists moderate-to-severe asthma as one of the risk factors for morbidity and mortality for COVID-19. ${ }^{2}$

Since there is no proper treatment for asthma still, the majority of asthma treatment aims at reducing the symptoms by ameliorating the inflammatory processes. ${ }^{3,4}$ To date, current asthma therapies mainly focus on pulmonary, followed by oral or intravenous administrations where beta-adrenoceptor-2 ( $\beta 2)$ agonists, corticosteroids as well as xanthines and their derivatives are drugs of choice. The treatments of choice are indeed $\beta 2$ agonists for symptomatic relief from asthma. ${ }^{4,5}$ Nevertheless, the current available anti-asthmatic drugs produce numerous side effects, including headaches, nausea, convulsions (xanthines), ${ }^{6}$ cardiovascular effects ( $\beta 2$ agonists), ${ }^{7}$ vomiting (phosphodiesterase type 4 inhibitors), ${ }^{8,9}$ adrenal suppression, myopathies, osteoporosis, and metabolic disturbances, while the use of corticosteroids may compromise children's growth. ${ }^{6,8,10,11}$ As such, natural products are therefore a good alternative to be explored. ${ }^{12}$

Embelin (2,5-dihydroxy-3-undecyl-1,4-benzoquinone), a major constituent of Embelia ribes Burm, has a broad range of pharmacological properties, including anticonvulsant, antidiabetic, anticancer, antifertility, neuroprotective, antihyperlipidemic, cardioprotective, antioxidant, analgesic, wound healing and anti-inflammatory effects. ${ }^{13}$ Our earlier research indicated that embelin is protective against acetic acid-induced ulcerative colitis in rats. ${ }^{14}$ Embelin has also been demonstrated to confer some protective effects against acute respiratory distress syndrome (ARDS) induced by lipopolysaccharide (LPS) in rats. ${ }^{15}$ Lee et al ${ }^{16}$ confirmed the anti-inflammatory effects of embelin on allergic asthma using lung adenocarcinoma cells (A549 cells) and asthmatic airway epithelial tissues occurring via inhibition of nuclear factor kappa-light-chainenhancer of activated B cells (NF-kB) activity. Further, Dai et $\mathrm{al}^{17}$ demonstrated anti-asthmatic activity of embelin against allergic asthma induced by ovalbumin (OVA) through inhibition of Th2 cytokines and NF-KB.

Several new animal models are currently available for preclinical screening to check the efficacy of antiasthmatic drugs. Thakur et al ${ }^{18}$ recently developed a new model to examine the anti-asthmatic effects in which the combination of OVA with LPS demonstrated the phenotypes of severe lymphocytic inflammation, neutrophilic, eosinophilic and bronchoconstriction, compared to a single allergen. Few other studies have also shown that pulmonary neutrophilia in the mouse is triggered by the combination of LPS with commercial OVA. ${ }^{19,20}$ On the other hand, OVA induces classical eosinophilic asthma, and OVA along with LPS induces neutrophilic and/or mixed-granulocytic asthma. ${ }^{21}$

Airway inflammation caused by recruitment of polymorphonuclear cells is closely linked to Th2-like cytokine upregulation. ${ }^{22}$ Differentiation of native $\mathrm{T}$ lymphocytes to Th2 cells is induced by primary secretion of IL-4 by basophils in the asthmatic mouse, which in turn secretes more IL-4 that facilitates Th2 differentiation. ${ }^{23,24}$ In addition, the primary synthesis of immunoglobulin $\mathrm{E}$ ( $\mathrm{IgE}$ ) also includes IL-4. ${ }^{25}$ It has been reported that IgE synthesis in OVA-induced mice is inhibited by anti-IL-4 and that $\operatorname{IgE}$ development in IL-4 ${ }^{-/-}$BALB/c mice is not asthma-associated. ${ }^{26}$ Similarly, the role of IL-5 in allergic inflammation is extremely significant, since the associations between IL-5 and asthma severity have been highlighted in several studies in OVA-induced mice asthma model. ${ }^{27}$ In a group of asthma patients, clinical trials of anti-IL-5 biological drugs (mepolizumab) have also shown beneficial effects. ${ }^{28} \mathrm{~A}$ strong inducer of eotaxin expression and mucus secretion is induced by another essential asthmatic cytokine, ie, IL-13. ${ }^{29}$

Among all the interleukins involved in the inflammatory process related to asthma, IL-13 is a potent activator. Several studies have documented the involvement of IL-13 signaling in hyper-regulation of mucin and fibrosis as well as in the upregulation of chitinase. In fact, IL-13 and IL-4 share similar biological roles in both signaling and the diverse network of receptors. ${ }^{30,31}$ Additionally, IL-13 plays an important role in controlling the inflammatory cells. IL-13 can induce IL-5 development in the smooth 
muscles of the lung airway, thus controlling the recruitment of eosinophils. ${ }^{32}$ Hence, embelin auto docked with IL-13 and their binding complementarities was evaluated in this study.

Embelin inhibits paraquat-induced oxidative stress in the lungs ${ }^{33}$ that is especially affected by COVID-19. In 2020 , Caruso et $\mathrm{al}^{34}$ stated that embelin and related quinones may be a viable strategic instrument against COVID-19. Some aspects of Th2 cytokines (IL-4 and IL13) and eosinophil accumulation may confer some protective effects against COVID-19. ${ }^{2}$ Embelin has previously been investigated in laboratory animal models for antiasthmatic action against either OVA- or LPS-induced acute asthma model. Asthma, however, is a chronic and multifactorial inflammatory disease, so asthma caused by a single allergen in an animal may not be a significant clinical asthma. Hence, the aim of the study was to evaluate the effect of embelin on severe airway inflammation of allergic asthma via Th2-mediated immune response in the OVA-LPS model.

\section{Methods}

\section{Chemicals}

Aluminum hydroxide $\left[\mathrm{Al}(\mathrm{OH})_{3}\right]$ gel, heparin, ketamine, OVA, LPS and all the other chemicals and reagents were of analytical grade.

\section{Animals}

Male Wistar albino rats (6-7 weeks old, 200-250 g) were procured from Zydus Research Center (ZRC), Ahmedabad, India, at 1 week before the study. The rats were accommodated with free access to a regular pellet diet and water ad libitum at a constant temperature (22 \pm $1^{\circ} \mathrm{C}$ ) with a relative humidity $(55 \pm 5 \%)$ and $12 / 12 \mathrm{~h} \mathrm{light/}$ dark cycle. The experimental protocol was approved by the Institutional Animal Ethical Committee, L. M. College of Pharmacy, Ahmedabad, India (LMCP/COLOGY/20/01) and followed the guidelines of Committee for the Purpose of Control and Supervision of Experiments on Animals (CPCSEA), Ministry of Social Justice and Empowerment, Government of India.

\section{Isolation of Embelin from Embelia ribes}

Embelin (Figure 1) was isolated from Embelia ribes seeds and was purified based on our earlier published protocol. ${ }^{35}$ The purity of the isolated embelin was confirmed by highperformance thin layer chromatography (HPTLC) along

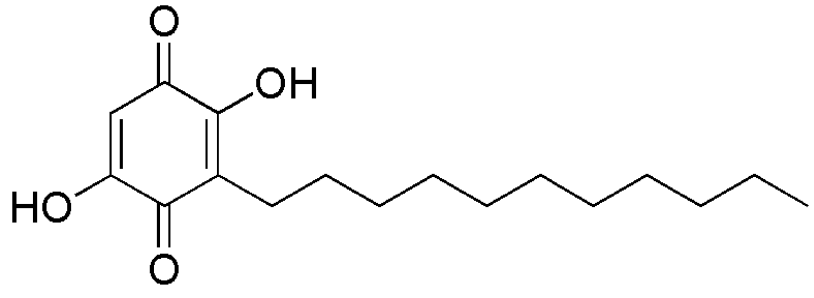

Figure I Chemical structure of embelin.

with authentic sample obtained from PhytoLab GmbH \& Co. KG, Vestenbergsgreuth, Germany. Ethyl acetate:benzene (70:30) was used as a solvent system. The pure sample of embelin was stored at $15-25^{\circ} \mathrm{C}$ until further use.

\section{Acclimatization}

In order to obtain a baseline data of lung function parameters prior to start of the analysis, all rats were acclimatized for $2 \mathrm{~min} /$ day for 7 days in a restrained condition.

\section{Criteria for Animal Selection}

The rats $(n=36)(200-250 \mathrm{~g})$ were randomised into six groups based on the below experimental design. The body weight differences between the groups were not greater than $\pm 20 \%$ of the mean body weight at the beginning of the experiment.

\section{Experimental Design and Study Protocol} Group-1 (G1): Normal control

Group-2 (G2): Disease control (OVA-LPS-induced asthmatic rats)

Group-3 (G3): OVA-LPS + Embelin (12.5 mg/kg, P.O.)

Group-4 (G4): OVA-LPS + Embelin (25 mg/kg, P.O.)

Group-5 (G5): OVA-LPS + Embelin (50 mg/kg, P.O.)

Group-6 (G6): Positive control [OVA-LPS + Dexamethasone (2.5 mg/kg, P.O.)]

Asthma was induced in rats by sensitisation with OVA and LPS $(100 \mu \mathrm{g} / \mathrm{kg}$, i.p., adsorbed in $100 \mathrm{mg} / \mathrm{mL}$ aluminium hydroxide $\left[\mathrm{Al}(\mathrm{OH})_{3}\right]$ and $10 \mu \mathrm{g} / \mathrm{kg}$, i.p., respectively) on day 7, 14 and 21 . The process was followed by a $30 \mathrm{~min}$ OVA $(0.5 \% \mathrm{w} / \mathrm{v})$ and LPS $(0.5 \% \mathrm{w} / \mathrm{v})$ challenge for 3 weeks, three times/week. A 10 min time interval between OVA and LPS administration was allowed during sensitisation. For the challenge, the rats were positioned into a plastic chamber attached with nebulizer (diameter $70 \mathrm{~cm}$, height $40 \mathrm{~cm}$ ) (CX4-Omron Healthcare, Kyoto, Japan) administering an aerosol delivery at $0.22 \mathrm{~mL} / \mathrm{min}$ 
The rats were sensitised and challenged with i.p. injection and aerosolised, respectively, with saline in the normal control group. On the $27^{\text {th }}$ day of the study, treatment with embelin (12.5, 25 and $50 \mathrm{mg} / \mathrm{kg} / \mathrm{day}$, P.O.) and dexamethasone (2.5 mg/kg/day, P.O.) began for 15 days in the respective groups (Figure 2). Subsequently, serum cytokine levels (IL-4, IL-5 and IL-13) were assessed at the end of the experiment using spectrophotometry-based kits (day 42), together with lung function parameters (respiration rate, tidal volume and airflow rate) using a volume transducer with Biopac, Acquisition Device, USA. Rats were acclimatized, $2 \mathrm{~min} /$ day for 7 days before measurement of lung function parameters were conducted.

On the same day, the total and differential leukocyte counts in the blood and BALF were determined. For that, rats were anaesthetized with ketamine $(24 \mathrm{mg} / \mathrm{kg}$, s.c.). A polypropylene cannula was then inserted into the trachea and a saline phosphate buffer $(10 \mathrm{~mL}$ of $0.9 \% \mathrm{w} / \mathrm{v})$ was subsequently introduced into the lungs with a $10 \mathrm{~mL}$ syringe at $37^{\circ} \mathrm{C}$. After $5 \mathrm{~min}$, BALF $(\approx 5 \mathrm{~mL})$ was recovered and was centrifuged at $5000 \mathrm{rpm}$ for $10 \mathrm{~min}$ at $4^{\circ} \mathrm{C}$. The resulting supernatant was stored $4{ }^{\circ} \mathrm{C}$ and retrieved the cells set down at the bottommost of the centrifuge tube.
The cell pellets were washed in $0.5 \mathrm{~mL}$ of saline and were subjected to the total and differential leukocytes count.

Blood (approximately $1000 \mu \mathrm{L}$ ) was withdrawn from the retro-orbital plexus of anaesthetized rats (under mild anaesthesia). They were kept at room temperature for 30 $60 \mathrm{~min}$ before centrifugation $(15 \mathrm{~min}$ at $1000 \mathrm{~g})$. Subsequently, the serum was aspirated.

Histological study of the lungs was also conducted on the final day of the study protocol. The dissected lung tissues were washed using normal saline and then placed in a $10 \%(\mathrm{v} / \mathrm{v})$ formaldehyde solution (Formalin). Lung specimens were cut and dyed with hematoxylin and eosin dye following tissue fixation. ${ }^{36,37}$ Using a zoom digital camera (MLX, Magnus, China), photographs of selected parts were taken at $10 \mathrm{x}$ magnifications.

\section{Molecular Docking with IL- I3}

A docking study was conducted by using SOFTWARE BIOVIA DISCOVERY STUDIO 19.0. Embelin and dexamethasone were docked with protein PDB ID 3L5X (crystal structure of IL-13 complexed with H2L6 FAB). The molecular docking was run by a CDOCKER automated flexible docking protocol. The study was conducted

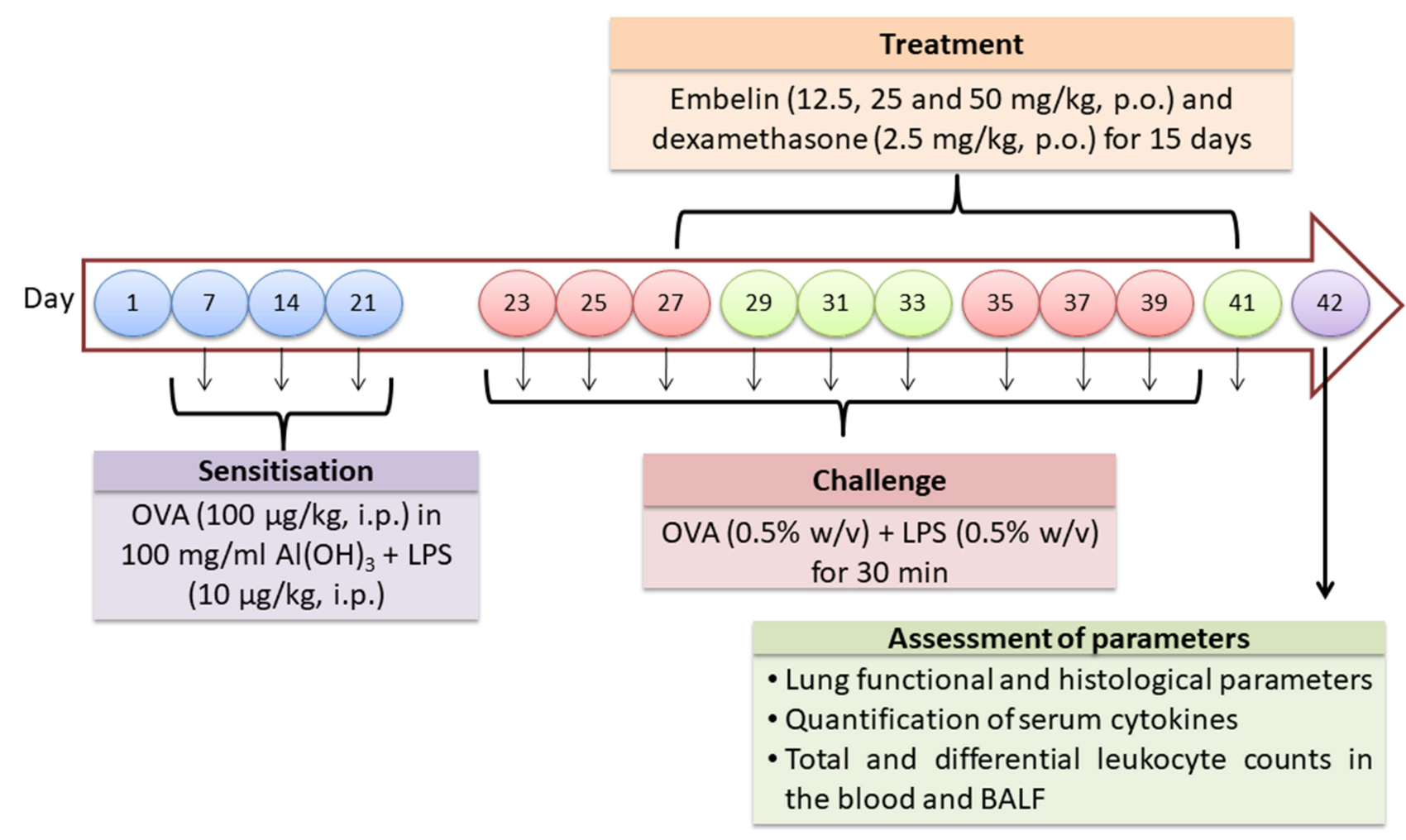

Figure 2 Study protocol followed to evaluate the effect of embelin against OVA-LPS-induced asthma model. 
to understand the yielded anti-asthmatic screening results of embelin and standard dexamethasone.

Subsequently, the structures of embelin and dexamethasone were constructed using ChemBioDrawUtra 12.0. Then, minimization of energy of each ligand pose was completed by CHARMm force field using CDOCKER protocol 10. The highest scored complex for each binding site was calculated as CDOCKER energy $(\mathrm{kcal} / \mathrm{mol})$ and was used for analysis. Other parameters were also observed, including the binding, ligand, protein and complexing energies of both the ligands. In this study, 3D conformers of embelin and dexamethasone were docked with the active site of the target protein 3L5X (IL-13). Then, 3L5X was used as a 3D co-crystal structure template for complexing embelin and dexamethasone on the target sites.

\section{Statistical Analysis}

All data obtained from the experiments were expressed as mean \pm SEM. Statistical analysis was performed by a oneway ANOVA, followed by Tukey's test using GraphPad Prism 5.0. A p-value of $<0.05$ was considered as statistically significant.

\section{Results}

The dose of embelin (12.5, 25 and $50 \mathrm{mg} / \mathrm{kg} /$ day, P.O.) in the present study was selected based on our previous acute and chronic toxicity studies. ${ }^{38}$ Apart from that, one of the very earlier studies on embelin (10-3000 mg/kg, P.O.) administration to experimental animals did not indicate any toxicity where $10 \mathrm{mg} / \mathrm{kg}$ of embelin in oral administration to rats for 10 weeks did not confer any toxicity on various organs, and exhibited a wide safety margin. ${ }^{39}$ The official Ayurvedic Pharmacopoeia and Indian Herbal Pharmacopoeia deemed Embelia ribes fruits powder (5$10 \mathrm{~g})$ as safe with no side effects. ${ }^{40,41}$ In another study, acute toxicity tests in embelin-treated mice at oral doses of 50 and $100 \mathrm{mg} / \mathrm{kg}$ showed no substantial improvement in both the mice's body weight and mortality, again suggesting its safety. ${ }^{42}$ Based on all these studies, the selected embelin doses used in this study is deemed to be safe.

\section{Effect of Embelin on Total and Differential Leukocyte Count in Blood and BALF}

When compared to normal control, there was a significant increase in the number of total and differential leukocyte counts, including neutrophils, eosinophils, lymphocytes and monocytes in the blood as well as in BALF of OVALPS-induced asthmatic rats (Figures 3 and 4). These changes are significantly reduced in rats that received embelin (25 and $50 \mathrm{mg} / \mathrm{kg}$ ) and standard dexamethasone $(2.5 \mathrm{mg} / \mathrm{kg})$ treatments. However, administration of embelin at $12.5 \mathrm{mg} / \mathrm{kg}$ did not confer any significant differences in the cell counts when compared to OVA-LPS-induced asthmatic rats. Moreover, embelin (25 and $50 \mathrm{mg} / \mathrm{kg}$ ) did not significantly reduce the number of total and differential blood cell counts indicating that there was no dosedependent activity.

\section{Effect of Embelin on Lung Function Parameters}

Respiration rate was significantly increased in OVA-LPSinduced disease control group as compared to the normal group. Treatment groups received embelin ( 25 and $50 \mathrm{mg} /$ $\mathrm{kg}$ ), exhibited $29.52 \%$ and $24.91 \%$ decrease $(\mathrm{p}<0.01$ and $\mathrm{p}<0.05$ ), respectively, in respiratory rate as compared to OVA-LPS-induced disease control group (Figure 5). There was a significant reduction in the tidal volume $(\mathrm{p}<0.001)$ of OVA-LPS-induced disease control rats as compared to the normal group. Additionally, embelin at 25 and $50 \mathrm{mg} /$ $\mathrm{kg}$ markedly increased $(\mathrm{p}<0.001$ and $\mathrm{p}<0.05)$ the tidal volumes by $128.83 \%$ and $95.63 \%$, respectively, as compared to the OVA-LPS-induced asthmatic group. Similarly, the standard dexamethasone-treated rats exhibited improvement $(\mathrm{p}<0.001)$ in respiratory rate and tidal volume by $39.02 \%$ and $145.23 \%$, respectively. The airflow rate was significantly reduced $(\mathrm{p}<0.001)$ in the asthmatic rats as compared to normal control group. Animals, which received embelin at 25 and $50 \mathrm{mg} / \mathrm{kg}$, exhibited a $39.81 \%$ and $33.45 \%$ increase $(p<0.01$ and $p<0.05)$ in the airflow rate, respectively, as compared to OVA-LPS-induced asthmatic control. Similarly, comparisons with standard dexamethasone-treated animals $(2.5 \mathrm{mg} / \mathrm{kg}) \quad$ indicated improvement $(\mathrm{p}<0.001)$ in airflow rate by $46.45 \%$. Nevertheless, the significant modulation in lung function parameters was not seen in embelin when administered at a low dose $(12.5 \mathrm{mg} / \mathrm{kg})$ as compared to OVA-LPSinduced asthmatic group.

\section{Effect of Embelin on Cytokines}

There was a significant increase in serum level of proinflammatory cytokines, ie, IL-4, IL-5 and IL-13 $(p<0.001)$ in OVA-LPS-induced asthmatic disease control group as compared to the normal group (Figure 6). IL-4, 


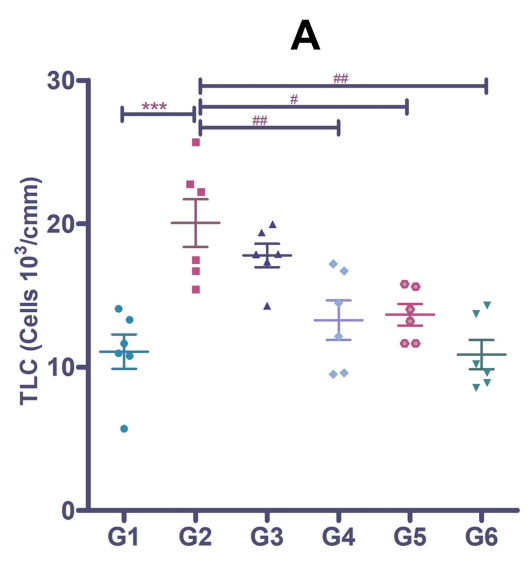

C

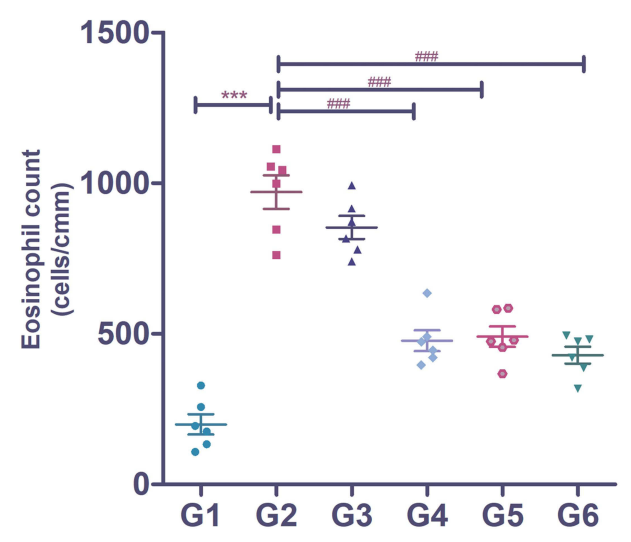

B

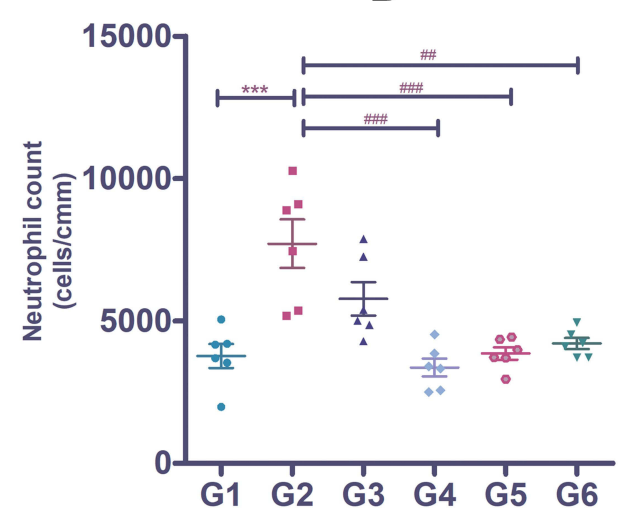

D

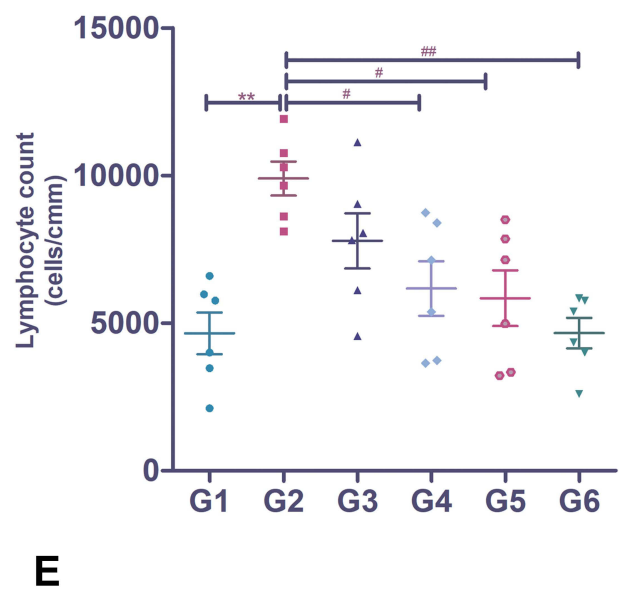

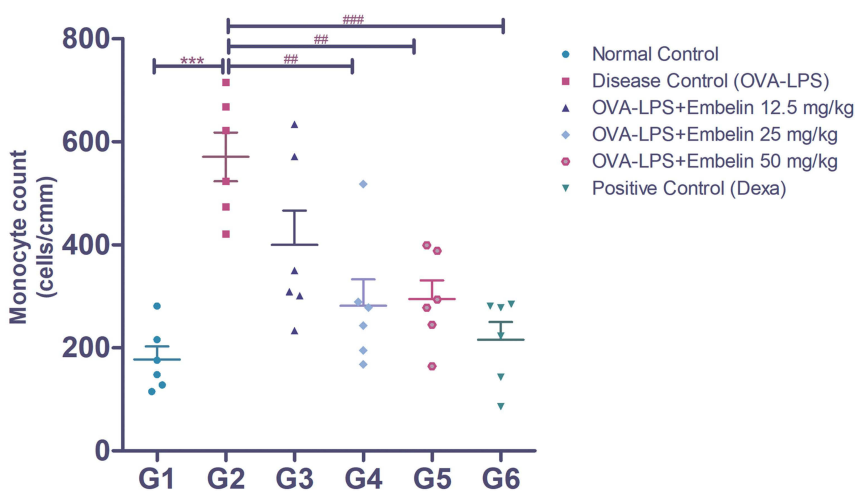

Figure 3 The effect of embelin on total and differential leukocyte counts in blood; (A) total leukocytes (TLC) (B) neutrophils (C) eosinophils (D) lymphocytes (E) monocytes. The values are presented as mean \pm SEM. ${ }^{* * *} \mathrm{p}<0.001$ compared with normal control group $\left(\mathrm{n}=6 /\right.$ group). ${ }^{\# \#} \mathrm{p}<0.00 \mathrm{I},{ }^{\# \#} \mathrm{p}<0.0 \mathrm{I},{ }^{\#} \mathrm{p}<0.05$ compared with OVALPS-induced asthmatic disease control group. $\mathrm{p}<0.05$ was considered as statistically significant.

IL-5 and IL-13 levels were significantly decreased $(\mathrm{p}<0.05, \mathrm{p}<0.001$ and $\mathrm{p}<0.01)$ in the embelin-treated groups (25 and $50 \mathrm{mg} / \mathrm{kg}$ ) as compared to OVA-LPSinduced asthmatic disease control group. Similar changes were seen in animals treated with standard dexamethasone $(2.5 \mathrm{mg} / \mathrm{kg})$, which exhibited a significant reduction in the levels of IL-4 $(\mathrm{p}<0.05)$, IL-5 $(\mathrm{p}<0.001)$ and IL-13 $(\mathrm{p}<0.001)$. Embelin administered at a low dose $(12.5 \mathrm{mg} / \mathrm{kg})$ did not cause any significant changes in IL-4, IL-5 and IL-13 levels as compared to OVA-LPSinduced asthmatic group. Additionally, there was no significant reduction in the levels of IL-4, IL-5 and IL-13 in animals administered with embelin (25 and $50 \mathrm{mg} / \mathrm{kg}$ ), again indicating that there is no dose-dependent activity, 
A

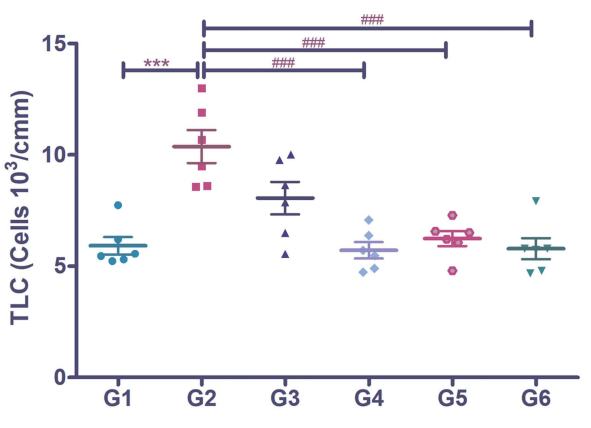

C

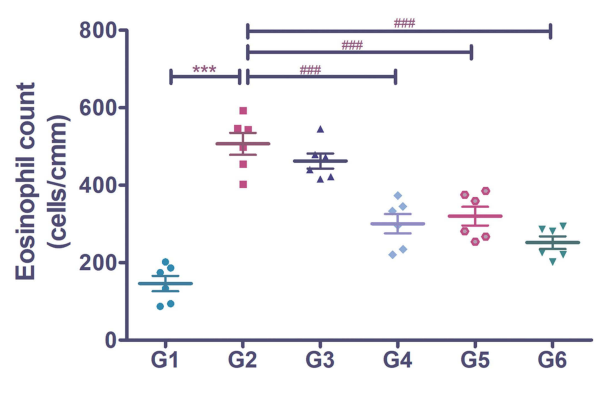

B
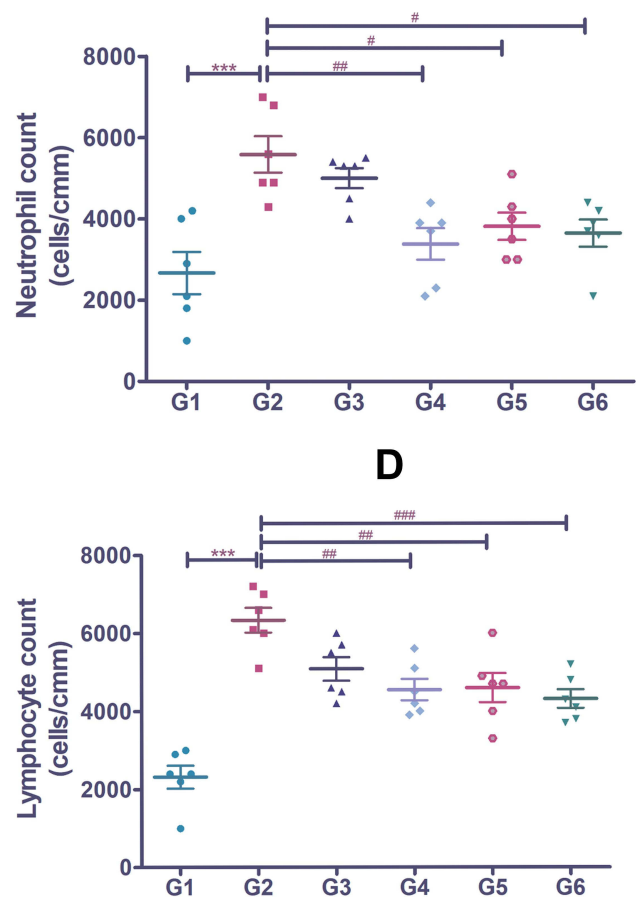

E

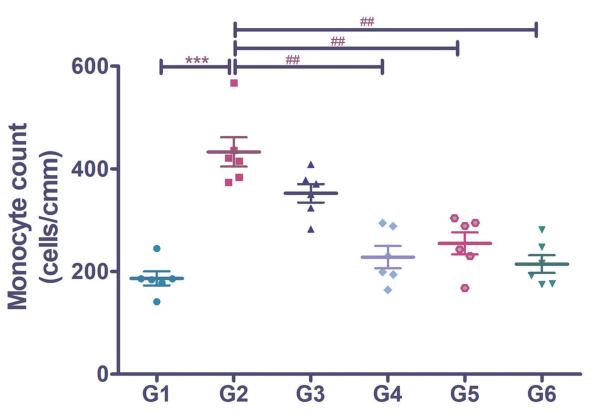

- Normal Control

- Disease Control (OVA-LPS)

- OVA-LPS+Embelin $12.5 \mathrm{mg} / \mathrm{kg}$

- OVA-LPS+Embelin 25 mg/kg

- OVA-LPS+Embelin 50 mg/kg

- Positive Control (Dexa)

Figure 4 Effect of embelin on total and differential leukocyte counts in BALF; (A) total leukocytes (TLC) (B) neutrophils (C) eosinophils (D) lymphocytes (E) monocytes.

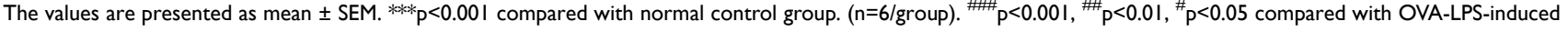
asthmatic disease control group. $\mathrm{p}<0.05$ was considered as statistically significant.

although the effects of embelin-treated groups were comparable with that of standard dexamethasone-treated group.

\section{Effect of Embelin on Architecture of Lung} Histologically, the normal control groups exhibited normal lung architecture. However, prominent infiltration of inflammatory cells was seen in the OVA-LPS-treated asthmatic control group (Figure 7). Nevertheless, administration of embelin $(25$ and $50 \mathrm{mg} / \mathrm{kg})$ and dexamethasone $(2.5 \mathrm{mg} / \mathrm{kg})$ reversed these changes but not at low-dose of embelin $(12.5 \mathrm{mg} / \mathrm{kg})$.

\section{Molecular Docking of Embelin with IL-I3 (3L5X)}

IL-13 plays a major role in causing inflammation during an asthmatic attack by bronchial constriction. Hence, molecular docking was performed to predict the interactive mode of embelin and dexamethasone to reveal novel information of the receptor protein and the ligand structure. Molecular docking study of the active sites for embelin and dexamethasone with 3L5X (Figure 8) was performed using a Discovery Studio 4.5 ACCERLYS software to assess and compare their binding scores and affinities with the co-crystallized ligand. 

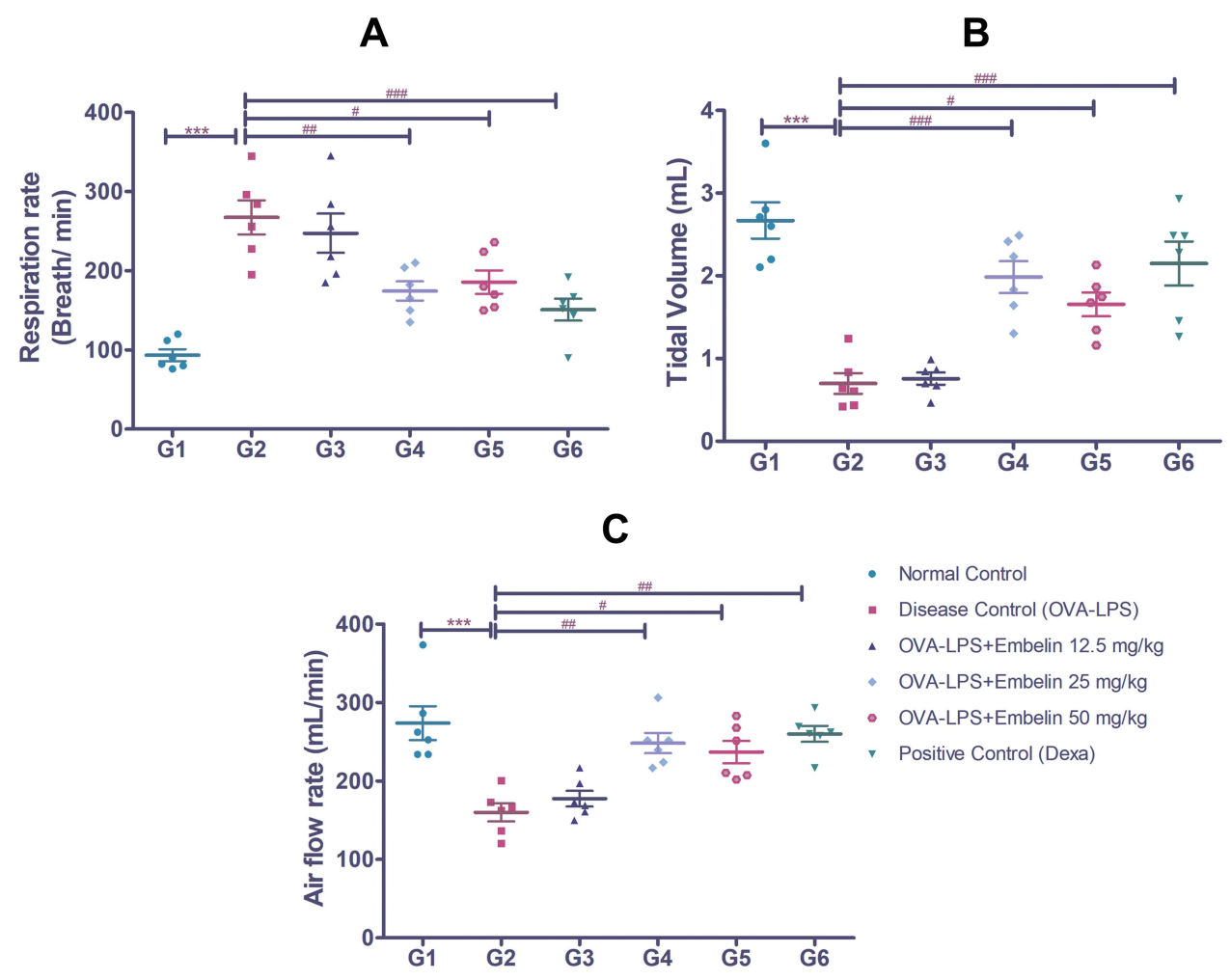

Figure 5 Effect of embelin on lung function parameters; $(\mathbf{A})$ respiration rate $(\mathbf{B})$ tidal volume $(\mathbf{C})$ airflow rate. The values are presented as mean \pm SEM. $* * * * 0.00$ I compared with normal control group ( $\mathrm{n}=6$ /group). $\mathrm{p}<0.00 \mathrm{I}, \mathrm{m}^{\mathrm{p}}<0.0 \mathrm{I},{ }_{\mathrm{p}}<0.05$ compared with OVA-LPS-induced asthmatic disease control group. $\mathrm{p}<0.05$ was considered as statistically significant.

Embelin forms two conventional hydrogen bonding interaction at 3L5X active site (Figure 8). The oxygen atom of the hydroxy group in embelin allows hydrogen bonding with hydrogen atom of ARG L: 61 (O-H-ARG L: 61). On the other hand, the hydrogen atom of the hydroxyl group of embelin forms a hydrogen bonding interaction with the hydrogen atom of GLU L: 79 (OH-O-GLU L:79). Other interactions including van der Waal's, carbon hydrogen bond and Pi-sigma interactions were also detected using a 2D representation (Figure 8). Dexamethasone has three conventional hydrogen bonding interactions, which are formed between the hydrogen atom from dexamethasone and the oxygen atom from GLU L: 81 and ARG L: 61 at the active site of PDB 3L5X (Figure 8). A carbon hydrogen bonding interaction was raised from the oxygen atom of dexamethasone with the hydrogen atom of amino acid residue GLU L: 79 (O-H-GLU L: 79). Some van der Waal's interactions were also detected in 3L5X and dexamethasone.

Based on the molecular docking study, the best docked pose for embelin and dexamethasone with $3 \mathrm{~L} 5 \mathrm{X}$ was as highlighted in Figure 9. The complex tend to show a good affinity to the $3 \mathrm{~L} 5 \mathrm{X}$ receptor protein, which may be contributed by both van der Waal and hydrogen bonding interactions. The binding, ligand, protein and complex energies of embelin and dexamethasone were as seen in Table 1 where the binding energies of embelin-3L5X and dexamethasone-3L5X complexes was $-19.16 \mathrm{kcal} / \mathrm{mol}$ and $-46.20 \mathrm{kcal} / \mathrm{mol}$, respectively. On the other hand, the CDOCKER interaction energy was at 18.04 (embelin3L5X) and $24.13 \mathrm{kcal} / \mathrm{mol}$ (dexamethasone-3L5X) (Table 2). Hence, based on the docking results, it can be confirmed that embelin may inhibit IL-13 (3L5X) protein where the anti-asthmatic activity may be due to inhibition of $3 \mathrm{~L} 5 \mathrm{X}$.

\section{Discussion}

To our knowledge, this is the first study to show that embelin alleviates severe airway inflammation of allergic asthma in OVA-LPS-induced rat model via by suppression of Th2-mediated immune response. Previous research on embelin showed a protective effect against LPS-induced ARDS in rats. ${ }^{15}$ Subsequently, Lee et al ${ }^{16}$ reported significant anti-inflammatory effects of embelin treatment in A549 cells occurring via inhibition of NF- $\mathrm{KB}$ activity on allergic asthma. Embelin was also reported to cause 


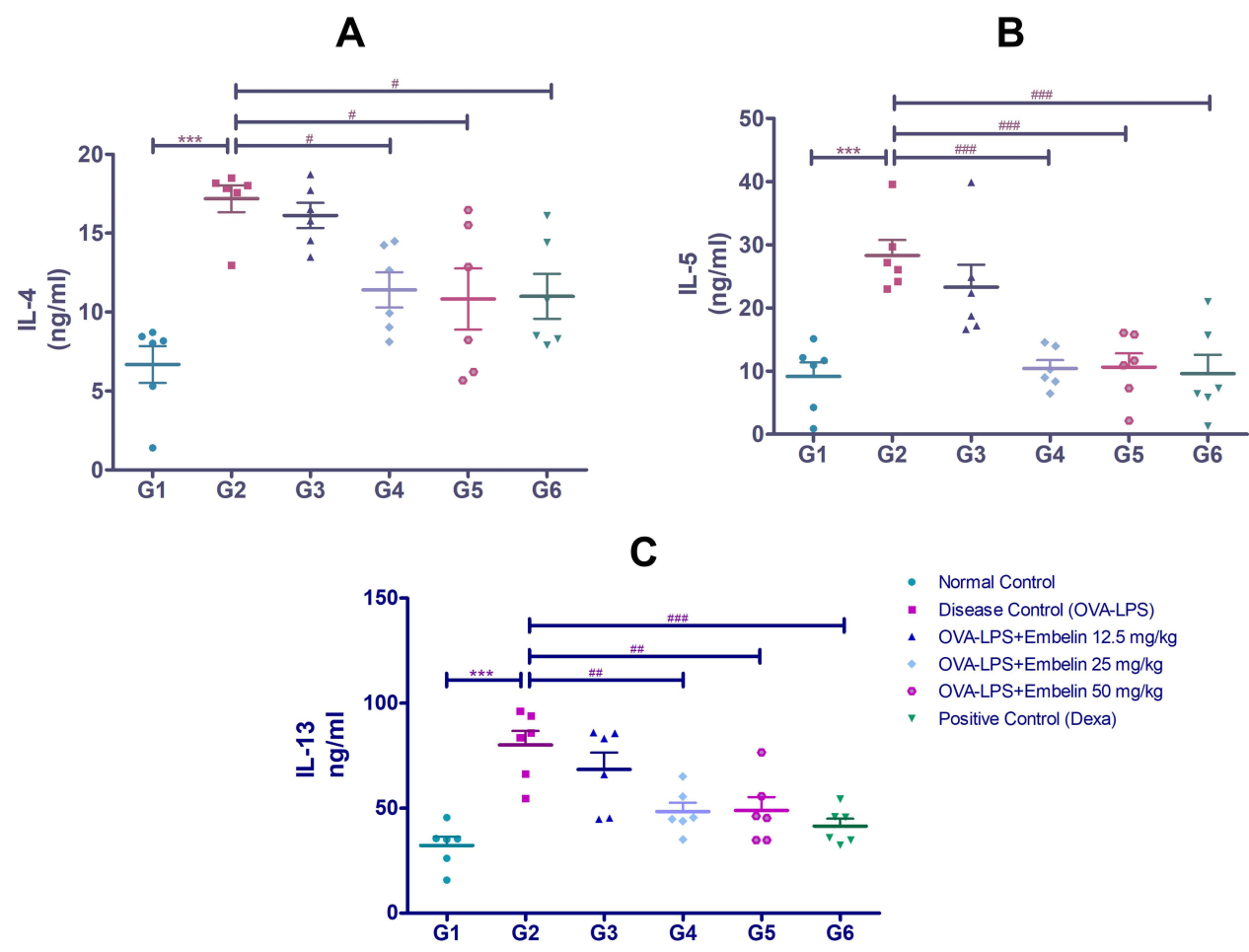

Figure 6 Effect of embelin on pro-inflammatory cytokines; (A) IL-4 (B) IL-5 (C) IL-13. The values are presented as mean \pm SEM. $* * *$ p $<0.00$ I compared with normal control group ( $\mathrm{n}=6$ /group). ${ }^{\#} \mathrm{p}<0.00 \mathrm{I},{ }^{\#} \mathrm{p}<0.0 \mathrm{I},{ }_{\mathrm{p}} \mathrm{p}<0.05$ compared with OVA-LPS-induced asthmatic disease control group. $\mathrm{p}<0.05$ was considered as statistically significant.

alleviation of OVA-induced allergic asthma by inhibition of Th2 cytokines and NF- $\mathrm{BB}^{17}$ indicating that overall, embelin has potential enough to test against severe allergic asthma on OVA-LPS-induced model.

Thakur et al $^{18}$ reported a new experimental model for anti-asthmatic study using OVA-LPS allergens in rats. In addition, they showed that OVA-LPS-induced animals indicated extreme bronchoconstriction with substantial variance in parameters of lung function compared to individual groups induced by OVA and LPS. There was a substantial increase in eosinophils, neutrophils and lymphocyte counts in the blood and BALF of OVA-LPS compared to the OVA- and LPS-induced groups. In addition, rats treated with OVA-LPS reported a significant increase in the levels of IL-4, IL-5 and IL-13 relative to the OVA- and LPS-induced groups.

Similar to previous findings, a rise in total leukocytes, particularly lymphocytes, monocytes, eosinophils and neutrophils in the blood and BALF of rats subjected to OVALPS was observed. ${ }^{18}$ Nevertheless, following administration of embelin and standard dexamethasone, all the said parameters were suppressed. The outcome is consistent with previous LPS- ${ }^{15}$ and OVA-induced embelin ${ }^{17}$ asthma findings. However, the OVA-LPS mediated parameters in the blood and BALF were not dose-dependently attenuated and embelin $(25 \mathrm{mg} / \mathrm{kg})$ did not cause any significant difference in the total and differential leukocyte counts in blood as well as BALF.

In our research, OVA-LPS-induced rats showed a significant increase in respiration rate, accompanied by a decrease in tidal volume and airflow rate, which are characteristics suggesting bronchoconstriction. In addition, all animals demonstrated sneezing, hyper-rhinorrhea and irritability in the asthmatic control group. Nevertheless, some bronchodilatory effects were demonstrated by animals treated with embelin $(25 \mathrm{mg} / \mathrm{kg})$ and dexamethasone indicating some protective effects against bronchoconstriction. The improved parameters of pulmonary function following embellishment therapy could be attributed to a decreased inflammation of the airway resulting in decreased pulmonary resistance to airflow. Airway hyperresponsiveness with clinical symptoms of high breathing rate and decreased tidal volume is considered to be the primary goal in asthma treatment. ${ }^{43}$

In the pathophysiology of allergic diseases, including allergic asthma, Th2 cytokines, such as IL-4, IL-5 and IL$13,{ }^{16}$ play significant roles. Therefore, the role of $\mathrm{Th} 2$ cytokines has been the subject of many respiratory research 


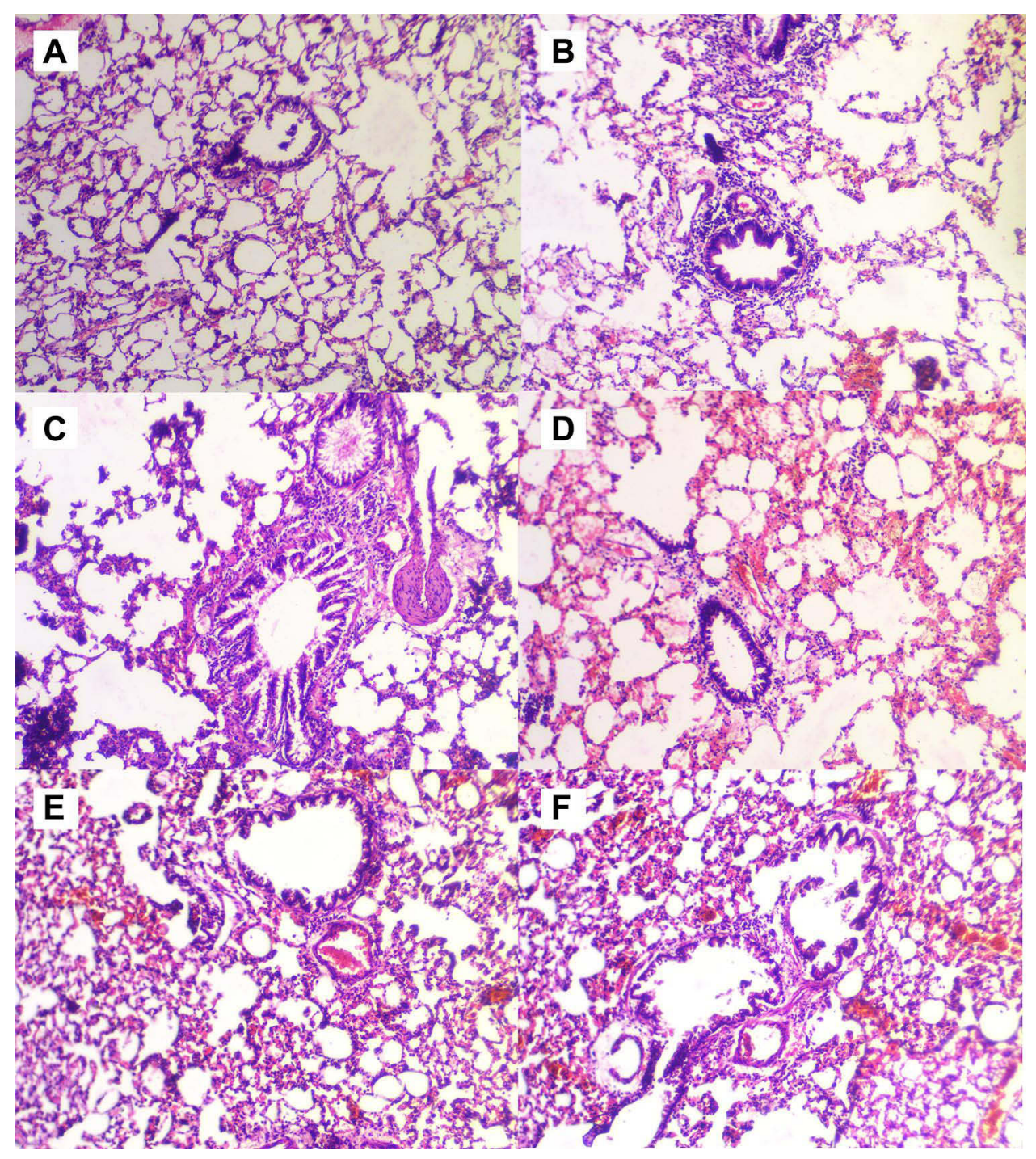

Figure 7 Effect of embelin on lung histopathology (photographs of selected parts were taken at I0x magnifications). (A) normal control (B) OVA-LPS-induced asthmatic disease control (C) OVA-LPS + embelin ( $12.5 \mathrm{mg} / \mathrm{kg})$, (D) OVA-LPS + embelin ( $25 \mathrm{mg} / \mathrm{kg})$, (E) OVA-LPS + embelin (50 mg/kg) and (F) OVA-LPS + dexamethasone (2.5 mg/ $\mathrm{kg})$-treated rats.

studies. IL-4 controls allergic inflammation by facilitating the differentiation of naive $\mathrm{T}$ cells into $\mathrm{Th} 2$ cells and induces $\mathrm{IgE}$ synthesis via activation of $\mathrm{B}$ cells. $^{44,45}$ Furthermore, the regulatory role of IL-4 and IL-5 on growth and differentiate eosinophils have been reported. ${ }^{46}$ IL-13 behaves similarly with IL-4, by inducing the synthesis of IgE in allergic asthma conditions. The function of IL-4 and IL-13 varies, as differentiate naive T cells into Th2 cells does not cause regulation of IL-13. Embelin treatment has the potential to minimize IgE levels and increase the status of antioxidants in the asthma model induced by OVA. ${ }^{17}$ In the current study, embelin significantly decreased the levels of IL-4, IL-5 and IL-13 indicating that it modulates IgE synthesis by blocking differentiate naive $\mathrm{T}$ cells into Th2 cells followed by IL-4 secretion (Figure 10). The NFкB-mediated pro-inflammatory cytokines are inhibited by embelin, comparable to the effects of the standard dexamethasone, which is commonly used as a medication for allergic asthma. The outcome of the present study is well correlated with previous findings on inhibitory effect of embelin on NF-KB activation in inflamed A549 cells and also with the study conducted in OVA-induced asthma model ${ }^{16,17}$ confirming the potential of embelin in ameliorating allergic asthma.

It has been postulated that in addition to suppressing the development of Th1 cells from Th0 cells, some of the Th2 cytokines, especially IL-4, also inhibit the production of multiple pro-inflammatory cytokines. ${ }^{47,48}$ In addition, 

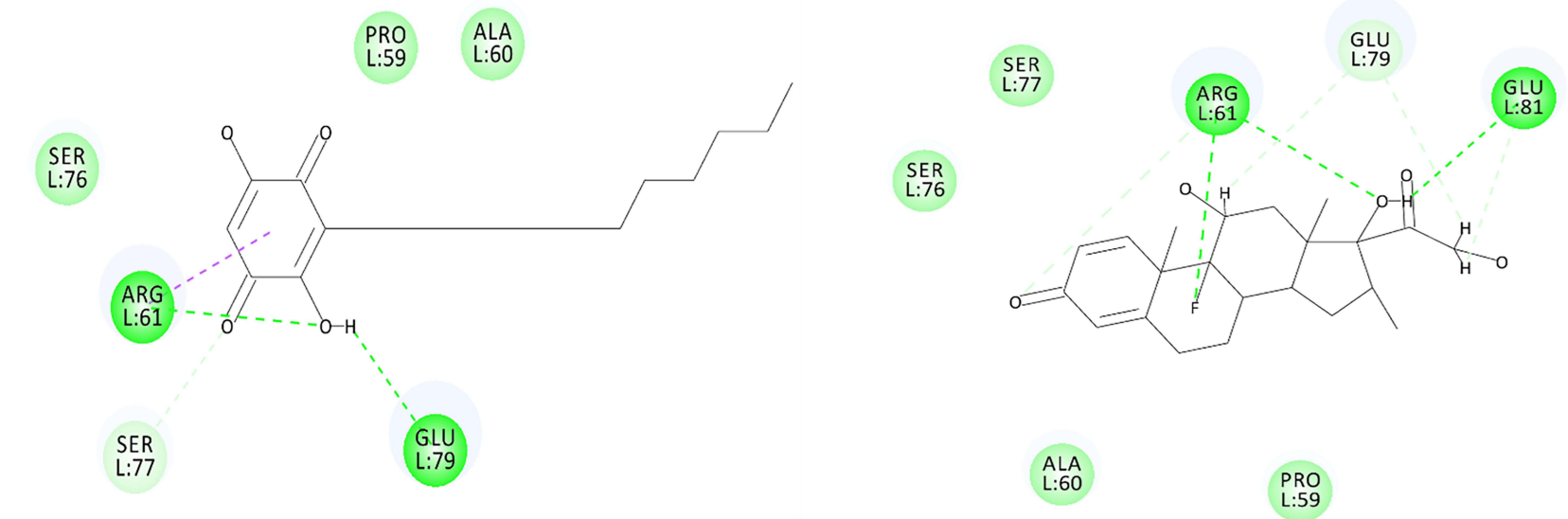

Interactions

$\square$ van der Waals

Conventional Hydrogen Bond

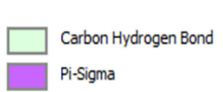

Interactions
\begin{tabular}{|l}
$\square$ van der Waals \\
Conventional Hydrogen Bond
\end{tabular}

Figure 8 A 2D-docked view of embelin and dexamethasone at the active site of the enzyme PDB ID: 3L5X.
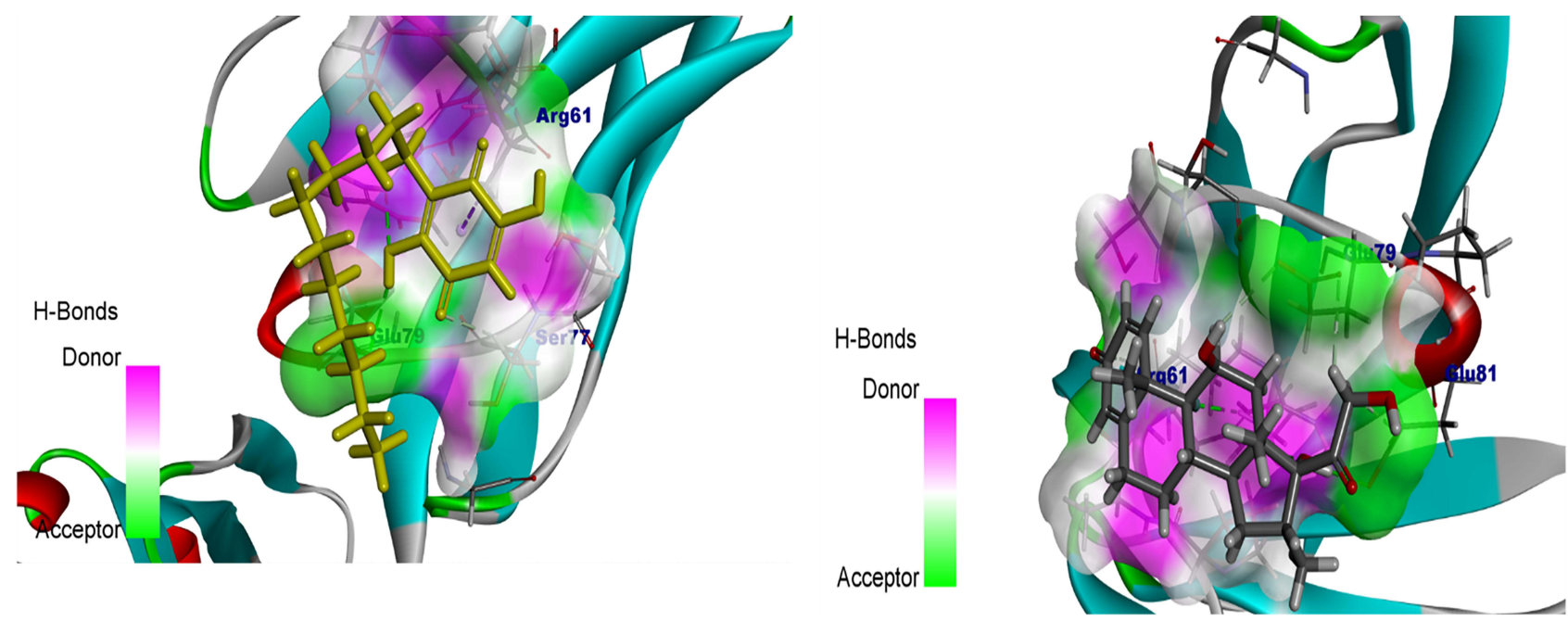

Figure 9 A 3D-docked view of embelin and dexamethasone at the active site of the enzyme PDB ID: 3L5X.

IL-13 mediated inhibition of the secretion of inflammatory cytokines and chemokines has been reported. ${ }^{49}$ Thus, it is plausible that predominance of $\mathrm{Th} 2$ cytokines, to some extent, can counteract the accumulation of inflammatory mediated cytokines, including those involved in the pathogenesis of COVID-19., ${ }^{2,50}$ Quinones are reactive to proteins containing cysteine residues and an active site that contains Cys145 is included in the main protease in COVID-19. ${ }^{34}$ Embelin as well as the associated quinones may also be a viable strategic instrument against COVID19 in the latest study. ${ }^{34}$ In the current research, we found that embelin significantly decreased IL-4, IL-5 and IL-13 secretions, thus suggesting that it can ameliorate the risk of asthmatics suffering from virus infection by further alleviating inflammation or strengthening antiviral defense. Additionally, this study investigated the presence of IL13 only in the serum. Since IL-13 is associated with histological changes, mucus and collagen deposition should ideally be evaluated in the tissue sections as well, which is another suggestion for future study.

When the lung tissues from the OVA-LPS-induced asthmatic group were histologically analysed, reduced bronchiolar lumen, infiltration of inflammatory cells into the peribronchial tissues and epithelial desquamation were seen. Embelin ( 25 and $50 \mathrm{mg} / \mathrm{kg}$ ) and standard dexamethasone $(2.5 \mathrm{mg} / \mathrm{kg})$ treatment conferred some protection 
Table I The Binding Energy of Ligand with PDB ID 3L5X

\begin{tabular}{|l|l|l|l|l|l|}
\hline Ligand Name & $\begin{array}{l}\text { Binding Energy } \\
\mathbf{( k c a l / m o l )}\end{array}$ & $\begin{array}{l}\text { Ligand Energy } \\
\mathbf{( k c a l / m o l )}\end{array}$ & $\begin{array}{l}\text { Protein Energy } \\
\mathbf{( k c a l / m o l )}\end{array}$ & $\begin{array}{l}\text { Complex Energy } \\
\mathbf{( k c a l / m o l )}\end{array}$ & $\begin{array}{l}\text { Entropic Energy } \\
\mathbf{( k c a l / m o l )}\end{array}$ \\
\hline Dexamethasone & -46.20 & 82.94 & -8549.07 & -8512.33 & 19.89 \\
Embelin & -19.16 & 0.43 & -8549.07 & -8567.80 & 19.38 \\
\hline
\end{tabular}

Table 2 Docked Results of Embelin and Dexamethasone with PDB ID 3L5X

\begin{tabular}{|l|l|l|}
\hline Ligand Name & $\begin{array}{l}\text { CDOCKER } \\
\text { Binding Energy }\end{array}$ & $\begin{array}{l}\text { CDOCKER } \\
\text { Interaction Energy }\end{array}$ \\
\hline $\begin{array}{l}\text { Dexamethasone } \\
\text { Embelin }\end{array}$ & -40.43 & 24.13 \\
\hline
\end{tabular}

against all of these pathological structures, as demonstrated by the increased lumen size and decreased immune cell infiltration, and these observations are in consistent with previous studies conducted on embelin in rats against ARDS caused by LPS. ${ }^{15}$

The molecular docking study for embelin and dexamethasone indicated that the docking conformation occurred in proximity with each other. Additionally, two common residues of ARG L:61 and GLU L:79, which binds to both embelin as well as dexamethasone were elucidated. The docking pose analysis confirmed that embelin and dexamethasone have a similar binding residue in the binding pocket of IL-13 while the distribution of hydrogen donor and acceptors around the ligands in the binding pocket revealed that embelin may be one of the lead candidates that have similar affinity towards dexamethasone. Overall, these findings confirmed the therapeutic potential of embelin against asthma as supported by the in-vivo findings.

Overall, the results of our study on embelin against the asthma model induced by OVA-LPS and also previous findings of asthma models induced individually by OVA and LPS, ${ }^{15,17}$ suggested amelioration of allergic effects associated with the inflammatory processes in embelintreated asthmatic rats. Appropriate asthma exacerbation treatment consists of acute restoration of the lung function and prevention of disease worsening. ${ }^{51}$ In the OVA-LPS mediated model, the current findings on embelin treatment showed significant restoration of lung function and prevention of asthma progression. Collectively, all of the findings revealed the potential of embelin in severe asthma, which should be further investigated in the development of novel formulations.
The current COVID-19 pandemic is frightening, with a great concern in individuals with asthma who may have a worse outcome or are more prone to the severe form of SARS-CoV-2. A study has indicated that asthma can increase the risk of COVID-19 hospitalisation in adults aged 18-49 years, although the study is focused only on a small number of patients. ${ }^{52}$ Nevertheless, the potential protective effects of embelin against COVID-19 could be provided by certain aspects of these cytokines and eosinophil accumulation. Embelin can reduce the risk of asthmatic patients suffering from virus infection by alleviating inflammation or improving antiviral defense. Therefore, future study should focus on investigating embelin against COVID-19, since it may be a potent compound against asthmatic patients suffering from viral infections.

\section{Conclusion}

Administration of embelin $(25 \mathrm{mg} / \mathrm{kg})$ significantly attenuated severe allergic asthma airway inflammation in the OVA-LPS-induced model by suppressing the recruitment of inflammatory cells, such as eosinophils, neutrophils, and monocytes. In addition, the immunological protective role of embelin can regulate the imbalance in Th2mediated cytokines by suppressing IL-4, IL-5 and IL-13 levels. A significant conformational adaptation between the complexes as well as the fact that embelin has a complementary binding efficiency to IL-13 relative to dexamethasone have been consistently discovered in the molecular docking study. In addition, embelin normalised the parameters of lung function. All these findings indicate that embelin is a promising therapeutic agent for severe allergic asthma, acting via regulation of Th2-mediated cytokine production. Further confirmation by conducting clinical trials as a promising natural product with the intention of developing as a natural anti-asthmatic medication would be awaited. It should be further explored against COVID-19 due to its positive effects in combating recruitment of eosinophils and secretion of proinflammatory cytokines. 


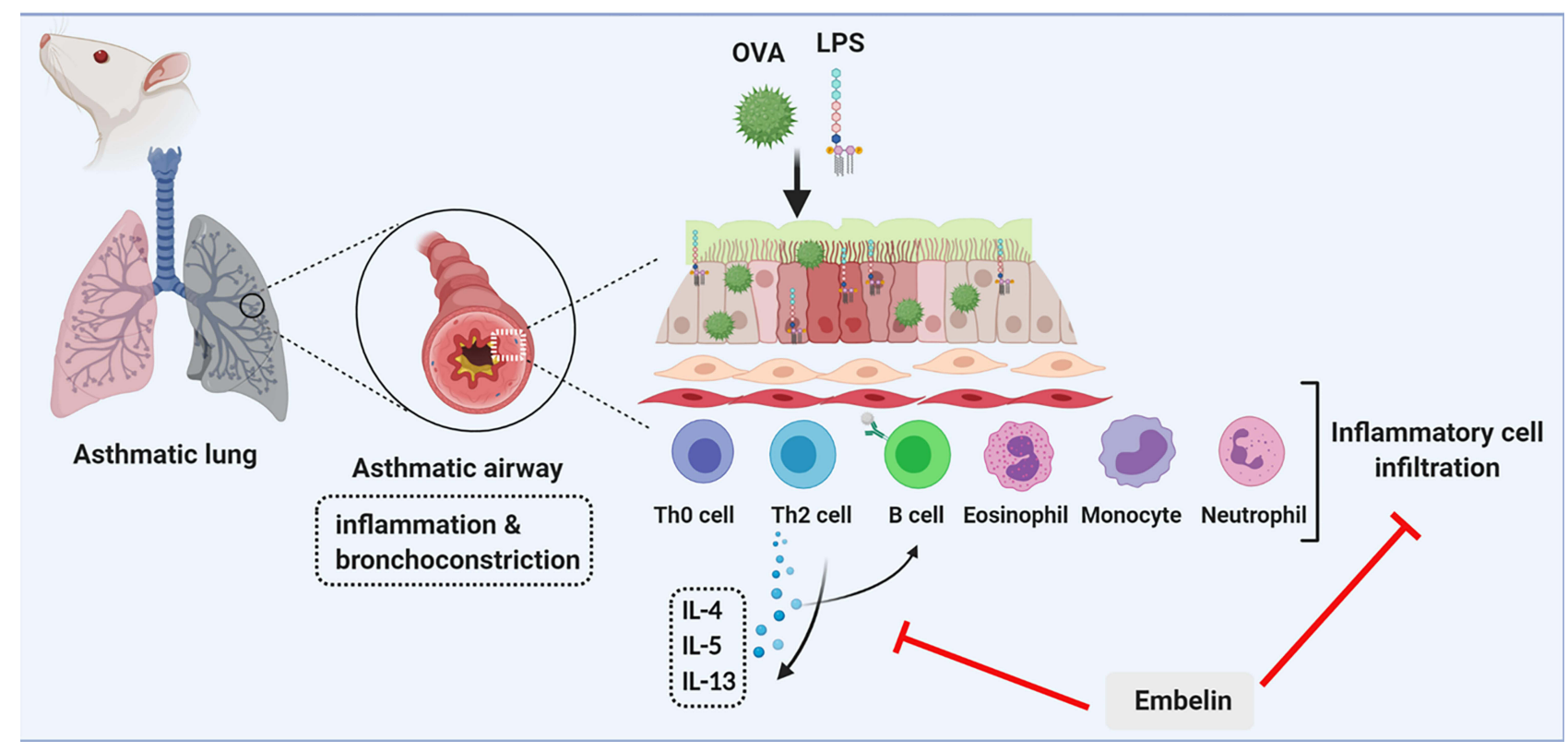

Figure 10 Possible mechanism of embelin against OVA-LPS-induced severe asthma in rats.

\section{Consent for Publication}

The final version of the manuscript was reviewed by all the authors and consented to its submission.

\section{Acknowledgments}

The authors appreciate Universiti Kuala Lumpur Royal College of Medicine Perak, Ipoh, Perak, Malaysia and L. M. College of Pharmacy, Ahmedabad, Gujarat, India, for providing the facilities and services required to complete the study. Figure 10 was created with the support of https://biorender.com under the paid subscription.

\section{Author Contributions}

S.A., M.S., and S.W. conceived the idea, designed, collected the literature, conducted the study, interpreted the data, analyzed the data, drafted and revised the manuscript. All the authors have made noteworthy contributions to the study design, data collection, review and interpretation; have engaged in the drafting or revision of the article; have agreed to submit to the current journal; have given final approval of the version to be published; and have agreed to be responsible for all aspects of the work.

\section{Funding}

There is no funding to report.

\section{Disclosure}

The authors have no conflict of interest associated with the publication. There is also no significant financial support for this work.

\section{References}

1. Global Initiative for Asthma. Global Strategy for Asthma Management and Prevention. Vol. 2020; 2016.

2. Liu S, Zhi Y, Ying S. COVID-19 and asthma: reflection during the pandemic. Clin Rev Allergy Immunol. 2020;59:78-88. doi:10.1007/ s12016-020-08797-3

3. Kaufman G. Asthma: pathophysiology, diagnosis and management. Nurs Stand. 2011;26(5):48. doi:10.7748/ns.26.5.48.s55

4. Pedersen SE, Hurd SS, Lemanske RF Jr, et al. Global strategy for the diagnosis and management of asthma in children 5 years and younger. Pediatr Pulmonol. 2011;46(1):1-17. doi:10.1002/ ppul.21321

5. Mohammed S, Goodacre S. Intravenous and nebulised magnesium sulphate for acute asthma: systematic review and meta-analysis. Emerg Med J. 2007;24(12):823-830. doi:10.1136/emj.2007.052050

6. Adams BK, Cydulka RK. Asthma evaluation and management. Emerg Med Clin N Am. 2003;21(2):315-330. doi:10.1016/S07338627(03)00015-4

7. Schaneberg BT, Crockett S, Bedir E, et al. The role of chemical fingerprinting: application to Ephedra. Phytochemistry. 2003;62 (6):911-918. doi:10.1016/S0031-9422(02)00716-1

8. Barnes PJ. Drugs for asthma. Br J Pharmacol. 2006;147(S1):S297S303. doi:10.1038/sj.bjp.0706437

9. Lugnier C. Cyclic nucleotide phosphodiesterase (PDE) superfamily: a new target for the development of specific therapeutic agents. Pharmacol Ther. 2006;109(3):366-398. doi:10.1016/j. pharmthera.2005.07.003

10. DiMartino SJ. Idiopathic inflammatory myopathy: treatment options. Curr Rheumatol Rep. 2008;10(4):321. doi:10.1007/s11926-008-0051-4 
11. Kesler SM, Sprenkle MD, David WS, et al. Severe weakness complicating status asthmaticus despite minimal duration of neuromuscular paralysis. Intensive Care Med. 2009;35(1):157-160. doi:10.1007/s00134-008-1267-5

12. Amaral-Machado L, Oliveira WN, Moreira-Oliveira SS, et al. Use of natural products in asthma treatment. Evid. Based Complementary Altern. Med. 2020;2020:1-35. doi:10.1155/2020/1021258

13. Othman SNN, Lum PT, Sekar M, et al. Molecules of interest-embelin-a review. Res J Pharm Technol. 2020;13(7):3485-3493. doi:10.5958/0974-360X.2020.00618.6

14. Thippeswamy BS, Mahendran S, Biradar MI, et al. Protective effect of embelin against acetic acid induced ulcerative colitis in rats. Eur J Pharmacol. 2011;654(1):100-105. doi:10.1016/j.ejphar.2010.12.012

15. Shirole R, Shirole NL, Saraf MN. Embelia ribes ameliorates lipopolysaccharide-induced acute respiratory distress syndrome. J Ethnopharmacol. 2015;168:356-363. doi:10.1016/j.jep.2015.03.009

16. Lee I-S, Cho D-H, Kim K-S, et al. Anti-inflammatory effects of embelin in A549 cells and human asthmatic airway epithelial tissues. Immunopharmacol Immunotoxicol. 2018;40(1):83-90. doi:10.1080/08923973.2017.1414836

17. Dai J, Ren M, Jiang M, et al. Embelin mitigates airway inflammation in ovalbumin induced asthma in a murine model. Lat Am J Pharm. 2018;37(10):1969-1976.

18. Thakur VR, Khuman V, Beladiya JV, et al. An experimental model of asthma in rats using ovalbumin and lipopolysaccharide allergens. Heliyon. 2019;5(11):e02864. doi:10.1016/j.heliyon.2019.e02864

19. Zhao S, Jiang Y, Yang X, et al. Lipopolysaccharides promote a shift from Th2-derived airway eosinophilic inflammation to Th17-derived neutrophilic inflammation in an ovalbumin-sensitized murine asthma model. J Asthma. 2017;54(5):447-455. doi:10.1080/02770903.2016. 1223687

20. Lowe A, Thomas RS, Nials A, et al. LPS exacerbates functional and inflammatory responses to ovalbumin and decreases sensitivity to inhaled fluticasone propionate in a Guinea pig model of asthma. $\mathrm{Br}$ J Pharmacol. 2015;172(10):2588-2603. doi:10.1111/bph.13080

21. Yu QL, Chen Z. Establishment of different experimental asthma models in mice. Exp Ther Med. 2018;15(3):2492-2498. doi:10.3892/etm.2018.5721

22. Kumar RK, Herbert C, Foster P. The "Classical" ovalbumin challenge model of asthma in mice. Curr. Drug Targets. 2008;9(6):485-494. doi:10.2174/138945008784533561

23. Khodoun MV, Orekhova T, Potter C, et al. Basophils initiate IL-4 production during a memory T-dependent response. J Exp Med. 2004;200(7):857-870. doi:10.1084/jem.20040598

24. Liu L, Rich BE, Inobe J-I, et al. Induction of Th2 cell differentiation in the primary immune response: dendritic cells isolated from adherent cell culture treated with IL-10 prime naive CD4+ T cells to secrete IL-4. Int Immunol. 1998;10(8):1017-1026. doi:10.1093/ intimm/10.8.1017

25. Finkelman FD, Urban JF Jr, Beckmann MP, et al. Regulation of murine in vivo $\mathrm{IgG}$ and $\mathrm{IgE}$ responses by a monoclonal anti-IL-4 receptor antibody. Int Immunol. 1991;3(6):599-607. doi:10.1093/ intimm/3.6.599

26. Grunewald SM, Werthmann A, Schnarr B, et al. An antagonistic IL-4 mutant prevents type I allergy in the mouse: inhibition of the IL-4/IL13 receptor system completely abrogates humoral immune response to allergen and development of allergic symptoms in vivo. J Immunol. 1998;160(8):4004-4009.

27. Hogan MB, Piktel D, Landreth KS. IL-5 production by bone marrow stromal cells: implications for eosinophilia associated with asthma. $J$ Allergy Clin Immunol. 2000;106(2):329-336. doi:10.1067/ mai.2000.108309

28. Pavord ID, Korn S, Howarth P, et al. Mepolizumab for severe eosinophilic asthma (DREAM): a multicentre, double-blind, placebo-controlled trial. The Lancet. 2012;380(9842):651-659. doi:10.1016/S0140-6736(12)60988-X
29. Gour N, Wills-Karp M. IL-4 and IL-13 signaling in allergic airway disease. Cytokine. 2015;75(1):68-78. doi:10.1016/j.cyto.2015.05.014

30. Wynn TA. IL-13 effector functions. Annu Rev Immunol. 2003;21 (1):425-456. doi:10.1146/annurev.immunol.21.120601.141142

31. Elias JA, Lee CG, Zheng T, et al. Interleukin-13 and leukotrienes: an intersection of pathogenetic schema. Am J Respir Cell Mol Biol. 2003;28(4):401-404. doi:10.1165/rcmb.F264

32. Wills-Karp M. Interleukin-13 in asthma pathogenesis. Immunol Rev. 2004;202(1):175-190. doi:10.1111/j.0105-2896.2004.00215.x

33. SreeHarsha N. Embelin impact on paraquat-induced lung injury through suppressing oxidative stress, inflammatory cascade, and MAPK/NF-KB signaling pathway. J Biochem Mol Toxicol. 2020;34 (4):e22456. doi:10.1002/jbt.22456

34. Caruso F, Rossi M, Pedersen JZ, et al. Computational studies reveal mechanism by which quinone derivatives can inhibit SARS-CoV-2. Study of embelin and two therapeutic compounds of interest, methyl prednisolone and dexamethasone. J Infect Public Health. 2020;13 (12):1868-1877. doi:10.1016/j.jiph.2020.09.015

35. Mahendran S, Badami S, Ravi S, et al. Synthesis and evaluation of analgesic and anti-inflammatory activities of most active antioxidant derivatives of embelin. J Pharm Res Int. 2014;58:2182-2199.

36. Garg K, Bahl I, Kaul M. A Textbook of Histology: A Colour Atlas and Text. CBS Publishers \& Distributors; 1999.

37. Kittel B, Ruehl-Fehlert C, Morawietz G, et al. Revised guides for organ sampling and trimming in rats and mice-Part 2: a joint publication of the RITA) and NACAD) groups. Exp Toxicol Pathol. 2004;55(6):413-431. doi:10.1078/0940-2993-00349

38. Mahendran S, Badami S, Maithili V. Evaluation of antidiabetic effect of embelin from Embelia ribes in alloxan induced diabetes in rats. Biomed Prev Nutr. 2011;1(1):25-31. doi:10.1016/j.bionut.2010.08.002

39. Rathinam K, Santhakumari G, Ramiah N. Studies on the antifertility activity of embelin. $J$ Res Ind Med. 1976;11:84-90.

40. Indian Herbal Pharmacopoeia. A Joint Publication of Regional Research Laboratories (CSIR) Jammu Tawi and Indian Drugs Manufacturer's Association. Mumbai: Indian Drug Manufacturers Association; 2002:206-213.

41. MoHFW. The Ayurvedic Pharmacopoeia of India. Part-I. New Delhi: Ministry of Health and Family Welfare, Department of AYUSH, Government of India; 1989:123-124.

42. Poojari R, Gupta S, Maru G, et al. Chemopreventive and hepatoprotective effects of embelin on N-nitrosodiethylamine and carbon tetrachloride induced preneoplasia and toxicity in rat liver. Asian Pac. J. Cancer Prev. 2010;11(4):1015-1020.

43. Mahajan SG, Mehta AA. Suppression of ovalbumin-induced Th2driven airway inflammation by $\beta$-sitosterol in a Guinea pig model of asthma. Eur J Pharmacol. 2011;650(1):458-464. doi:10.1016/j. ejphar.2010.09.075

44. Hershey GKK, Friedrich MF, Esswein LA, et al. The association of atopy with a gain-of-function mutation in the $\alpha$ subunit of the interleukin-4 receptor. $N$ Engl $J$ Med. 1997;337(24):1720-1725. doi:10.1056/NEJM199712113372403

45. Kim E, Kwon J-T, Lee D-H, et al. Ethylene glycol potentiated didecyldimethylammonium chloride toxicity in human bronchial epithelial cells. Mol Cell Toxicol. 2015;11(2):161-166. doi:10.1007/ s13273-015-0014-6

46. Kim YH, Park C-S, Lim DH, et al. Antiallergic effect of anti-Siglec$\mathrm{F}$ through reduction of eosinophilic inflammation in murine allergic rhinitis. Am J Rhinol Allergy. 2013;27(3):187-191. doi:10.2500/ ajra.2013.27.3866

47. Te Velde AA, Huijbens R, Heije K, et al. Interleukin-4 (IL-4) inhibits secretion of IL-1 beta, tumor necrosis factor alpha, and IL- 6 by human monocytes. Blood;1990. 1392-1397. doi:10.1182/blood. V76.7.1392.1392

48. Levings MK, Schrader JW. IL-4 inhibits the production of TNF- $\alpha$ and IL-12 by STAT6-dependent and-independent mechanisms. J Immunol. 1999;162(9):5224-5229. 
49. de Vries JE. The role of IL-13 and its receptor in allergy and inflammatory responses. $J$ Allergy Clin Immunol. 1998;102 (2):165-169. doi:10.1016/S0091-6749(98)70080-6

50. Bonam SR, Kaveri SV, Sakuntabhai A, et al. Adjunct immunotherapies for the management of severely ill COVID-19 patients. Cell Rep Med. 2020;1:100016. doi:10.1016/j.xcrm.2020.100016

51. Zaidan MF, Ameredes BT, Calhoun WJ. Management of acute asthma in adults in 2020. JAMA. 2020;323(6):563-564 doi:10.1001/jama.2019.19987
52. Garg S. Hospitalization rates and characteristics of patients hospitalized with laboratory-confirmed coronavirus disease 2019-COVIDNET, 14 States, March 1-30, 2020. Morbidity Mortality Weekly Rep. 2020;69:458.

\section{Publish your work in this journal}

The Journal of Asthma and Allergy is an international, peer-reviewed open-access journal publishing original research, reports, editorials and commentaries on the following topics: Asthma; Pulmonary physiology; Asthma related clinical health; Clinical immunology and the immunological basis of disease; Pharmacological interventions and new therapies. The manuscript management system is completely online and includes a very quick and fair peer-review system, which is all easy to use. Visit http://www.dovepress.com/testimonials.php to read real quotes from published authors.

Submit your manuscript here: https://www.dovepress.com/journal-of-asthma-and-allergy-journal 